\title{
A representação da identidade em Hell-Heaven, de Jhumpa Lahiri
}

\author{
Shirley de Souza Gomes Carreira ${ }^{1}$
}

Resumo: Este artigo visa à análise do conto "Hell-Heaven", de Jhumpa Lahiri, a fim de demonstrar como a autora aborda a questão da identidade do imigrante, bem como as sucessivas etapas do processo de integração ao país de adoção.

Palavras-chave: Identidade. Imigração. Transculturação.

\section{Introdução}

Jhumpa Lahiri, escritora descendente de indianos, nascida em Londres e educada nos Estados Unidos, tornou-se recentemente conhecida graças a dois livros de contos, Interpreter of maladies (1999) e Unaccustomed earth (2008) e um romance, The namesake (2003), que obtiveram sucesso de crítica e de público.

Seus textos transitam no vasto território das relações interculturais e encontram eco na experiência empírica de leitores que, sendo igualmente imigrantes, encontram-se na posição insólita de quem está no limiar de duas culturas diferentes. É desse entre-lugar que seus personagens se enunciam, nunca sob a forma de estereótipos, mas como indivíduos, que, em circunstâncias particulares, posicionam-se diferentemente quanto à questão da imigração.

De certo modo, Lahiri assume as características do escritor migrante definido por Salman Rushdie em Imaginary homelands ${ }^{2}$, uma vez que, a cada página, seus livros oferecem um vislumbre das dificuldades enfrentadas por imigrantes que, sob a pressão de culturas diversas, buscam definir-se identitariamente no país de adoção. Seus personagens são geralmente indianos ou descendentes de imigrantes indianos em um processo de crise de identidade, incapazes de lidar com um profundo sentimento de inadequação social.

Em Unaccustomed earth, Lahiri focaliza especialmente a problemática da integração de uma segunda geração de famílias imigrantes, nascida na América, dividida entre a manutenção da tradição e a necessidade de mudança, a fim de adequar-se ao American way of life.

\footnotetext{
${ }^{1}$ Shirley de Souza Gomes Carreira é doutora em Literatura Comparada (UFRJ) e atua como Professora Titular da UNIABEU, onde também edita as revistas eletrônicas e-scrita e Uniabeu. Tem trabalhos publicados no Brasil, México, Portugal, Estados Unidos, Itália e Inglaterra. Em 2011, organizou a coletânea Memória e identidade: ensaios (Galo Branco). É investigadora convidada do Centro de Estudos Linguísticos, Comparados e Multimídia da Universidade Autónoma de Lisboa. E-mail: shirleysgcarr@gmail.com

${ }^{2}$ Rushdie, ao falar de si como um escritor migrante, autointitulou-se um "homem traduzido".
} 
Neste artigo, o conto "Hell-Heaven" será analisado de modo a demonstrar como a autora aborda a questão da definição identitária e os processos inerentes à transculturação ${ }^{3}$.

\section{A saga do imigrante}

O conto "Hell-Heaven" focaliza etapas do processo de integração de um imigrante: a necessidade de adaptação, a luta para ser aceito socialmente, o choque entre culturas e, até mesmo, o ressentimento provocado pelas pressões familiares.

Em Imaginary homelands, Rushdie (1991, p. 277-8) afirma que um imigrante sofre, tradicionalmente, uma tripla ruptura: ele perde seu lugar antropológico ${ }^{4}$, adota um idioma diferente e encontra-se em um meio ambiente em que os códigos sociais não só divergem dos seus, mas podem, às vezes, ser desagradáveis ou mesmo ofensivos. As raízes, o idioma e as normas sociais são, assim, três importantes elementos constituintes da identidade cultural. Ao negá-los, o imigrante é compelido a encontrar novos meios de descrever-se e definir-se como indivíduo.

Segundo Berry (2003), o processo de aculturação compreende quatro variáveis: integração, assimilação, separação e marginalização. A história das migrações mundiais demonstra que, dentre elas, a integração é a variável mais comum. Estudos sobre a aculturação demonstram que, ao invés da mera assimilação à nova cultura, as minorias passam por um processo de integração que ocorre na forma de uma negociação, em via de mão dupla, com trocas culturais intensas, que dão origem a novas identidades.

Como escritor, Rushdie, que residiu em três países diferentes, além da Índia, Paquistão, Inglaterra e Estados Unidos, onde vive atualmente, tem demonstrado o quanto a sua identidade sofreu alterações em consequência das trocas culturais. Este, no entanto, não é o enfoque principal de Lahiri. Como Dominique Nagpal observa, a produção literária de Lahiri revela que o local a que alguém se encontra profundamente ligado não é necessariamente o país ao qual está atado por laços de sangue ou nascimento, e, sim, aquele que lhe dá a sensação de completude (NAGPAL, 2009, p. 2).

Entretanto, como qualquer processo de hibridismo é o resultado de uma negociação entre culturas, os filhos da primeira geração de imigrantes geralmente são obrigados a

\footnotetext{
${ }^{3} \mathrm{O}$ conceito de transculturação considerado como ponto de partida para este trabalho é o de mescla de culturas ocidentais e/ou não ocidentais, que proporcionam uma intensa troca cultural e o surgimento de identidades híbridas.

${ }^{4}$ Consideramos aqui a definição de Marc Augé, isto é, local de existência, residência e trabalho, que "é simultaneamente princípio de sentido para aqueles que o habitam e princípio de inteligibilidade para quem o observa" (AUGÉ, 1995, p. 51).
} 
enfrentar o seu estatuto de "hifenados", mítica de uma terra natal que não apenas é totalmente desconhecida, mas também representa justamente a parte perdida do hífen. Assim, o conceito de terra natal fica a meio termo entre uma idealização e o espaço empírico.

Ao ecoar sua dupla voz, de alguém que, sendo descendente de indianos, nasceu no ocidente, Lahiri cria um universo ficcional em que os personagens experimentam um sentimento paradoxal de atração e separação da terra natal coletivamente imaginada.

Conforme Huggan enfatiza, os escritores migrantes retratam indivíduos hifenados de modo a expurgar as suas identidades divididas (HUGGAN, 1996, p. 11).

\section{Uma história a ser contada}

Em "Hell-Heaven", a história é narrada em flashback, do ponto de vista de uma jovem que revisita a sua infância e reflete sobre as complexas relações entre os personagens. Ao longo do conto, os temas são bem delineados: os modos de vida conflitantes dos bengaleses e dos americanos, bem como a relação delicada entre mãe e filha.

A narradora, Usha, é a única filha de uma família de Bengala, cujo pai, Shyamal Da, fora para Boston para trabalhar e tentar enriquecer. Sua esposa, Aparna, sente a solidão causada por sua constante ausência, o que a faz negligenciar a educação de Usha segundo a tradição indiana.

Um dia, ao sair, elas encontram um jovem estudante do MIT, Pranab Kaku, e aos poucos ele se torna amigo da família, a ponto de ser aceito como um novo membro. Pranab pertencia a uma família rica de Calcutá e jamais havia feito coisa alguma "além de servir-se de um copo de água", antes de mudar para a América (LAHIRI, 2008, p. 62). Vivia em um sótão alugado na residência de uma senhora que tinha dois filhos barulhentos e não lhe dava permissão para usar a cozinha todas as horas do dia. Ao sentir-se cerceado em seus hábitos, Pranab quase abandonara os estudos. Assim, seu encontro com Aparna e Usha é providencial.

À medida que as visitas à residência de suas novas amigas tornam-se frequentes, mesmo na ausência de Shyamal, certa afinidade começa a surgir entre ele e Aparna, que é apenas três anos mais jovem. Consequentemente, ele passa a estar sempre por perto, disposto a ouvir suas

\footnotetext{
5 Há uma tendência, predominantemente norte-americana, de conceber a identidade de minorias como identidades "hifenadas". Assim, um negro americano é tratado como afroamericano, o que parece, no entanto, ter um efeito inverso ao pretendido, pois, ao invés de uni-las, mantém a separação entre duas matrizes culturais distintas.
} 
histórias e a conversar sobre o que têm em comum, como, por exemplo, o gosto musical, o interesse por cinema e poesia, coisas que Aparna e o marido não compartilham mais.

À época, a narradora era apenas uma criança e, apesar das evidências, foi incapaz de perceber que sua mãe se apaixonara pelo recém-chegado:

Ele apareceu sem avisar, sem telefonar antecipadamente, batendo simplesmente na porta, do modo como se faz em Calcutá, e gritando "Boudi!", enquanto esperava que minha mãe o deixasse entrar. Antes de o encontrarmos, eu voltava da escola e encontrava minha mãe com a bolsa no colo e de casaco, desesperada para escapar do apartamento onde havia passado o dia inteiro. Mas agora, eu a encontrava na cozinha, esticando a massa para os luchis, o que ela normalmente fazia apenas aos domingos para meu pai e eu, ou colocando cortinas novas que havia comprado em Woolworth's. Entendo agora, ao recordar-me, que as visitas de Pranab Kaku eram aquilo por que a minha mãe ansiava o dia inteiro (LAHIRY, 2008, p. $63) .^{6}$

As situações começam a se complicar quando um quinto personagem entra em cena. A integração de Pranab à nova terra é rápida e logo ele decide casar-se com uma ocidental, Deborah. Como a família do rapaz a rejeita, ele procura o apoio nos pais de Usha:

Ele havia contado aos seus pais sobre nós, e, em um determinado momento, meus pais receberam uma carta deles, expressando sua alegria por cuidarmos tão bem de seu filho e por dar-lhe uma casa apropriada na América. "Não precisa ser longa", Pranab disse, " Poucas linhas. Eles aceitarão melhor se partir de vocês." Meu pai não pensava nem bem nem mal de Deborah, nunca citando-a ou criticando-a, como minha mãe fazia, mas assegurou a Pranab Kaku que a carta de apoio estaria a caminho de Calcutá no fim da semana. Minha mãe concordou, mas no dia seguinte eu vi a xícara que Pranab Kaku usava todo o tempo como cinzeiro na lata de lixo da cozinha, em pedaços, e três Band-Aids na mão de minha mãe (LAHIRI, 2008, p. 71). ${ }^{7}$

\footnotetext{
6 "He appeared without warning, never phoning beforehand but simply knocking on the door the way people did in Calcutta and calling out "Boudi!" as he waited for my mother to let him in. Before we met him, I would return from school and find my mother with her purse in her lap and her trench coat on, desperate to escape the apartment where she had spent the day alone. But now I would find her in the kitchen, rolling out dough for luchis, which she normally made only on Sundays for my father and me, or putting up new curtains she'd bought at Woolworth's. I did nit know, back then, that Pranab Kaku's visits were what my mother looked forward to all day" (Nossa tradução).

${ }^{7} \mathrm{He}$ had told his parents all about us, and at one point my parents had received a letter from them, expressing appreciation for taking such good care of their son and for giving him a proper home in America. "It needn't be long," Pranab Kaku said. "Just a few lines. They'll accept it more easily if it comes from you." My father thought neither ill nor well of Deborah, never commenting or criticizing as my mother did, but he assured Pranab Kaku that a letter of endorsement would be on its way to Calcutta by the end of the week. My mother nodded her assent, but the following day I saw the teacup Pranab Kaku had used all this time as an ashtray in the kitchen garbage can, in pieces, and three Band-Aids taped to my mother's hand (Nossa tradução).
} 
Aparna mantém as aparências, apesar de todo o sofrimento que a situação lhe causa, e concede o apoio solicitado, prevendo, no entanto, que o casamento não iria durar muito, o que de fato acontece, muitos anos mais tarde, devido à infidelidade de Pranab. Este parece ignorar completamente os sentimentos da amiga, considerando-a como uma irmã mais velha. No entanto, para ela, os sentimentos têm outro significado. Seu casamento com Shyamal fora parte de um acordo, cuja finalidade era obter a permissão da família do noivo para que ele pudesse emigrar para a América.

A distância entre marido e mulher revela-se objetivamente no fato de que ela jamais o chama pelo nome, como faz com Pranab. A carreira de Shyamal é o centro de sua vida, uma espécie de concha, na qual nem Aparna nem Usha conseguem penetrar. A sua natureza friamente intelectual não o deixa perceber as carências da esposa, criando, na vida já limitada desta, um vazio que aumenta com o passar do tempo:

A conversa era uma obrigação para ele; requeria um esforço que ele preferia fazer no laboratório. Ele detestava os excessos, não concebia nada além dos elementos frugais de sua rotina: chá e cereais pela manhã, uma xícara de chá após chegar a casa, e dois pratos de vegetais diferentes ao jantar. Ele não comia com o apetite descuidado de Pranab Kaku. Meu pai tinha uma mentalidade de sobrevivente (LAHIRI, 2008, p. 65). ${ }^{8}$

A diferença entre os dois homens acentua-se à medida que Pranab passa a ficar mais próximo da família. À complicada situação, soma-se o fato de que ele e Aparna eram da mesma região ao norte de Calcutá e compartilhavam costumes e lembranças. Shyamal, por sua vez, vinha de um subúrbio distante, um lugar que Aparna considerava agreste e detestável a ponto de agradecer por estar na América, mesmo nas horas em que sentia saudade da terra natal. No local de nascimento do marido, as esposas eram uma espécie de prisioneiras. Assim, aos olhos de Aparna, Pranab era mais do que o homem por quem ela estava apaixonada; significava um retorno às suas próprias raízes:

Em poucas semanas, Pranab Kaku havia mudado para o nosso apartamento, e ele tocava para minha mãe vários pout pourris de canções de filmes indianos da sua juventude. Eram canções alegres de amor, que transformavam a vida quieta em nosso apartamento e transportavam minha

\footnotetext{
8 "Conversation was a chore for him; it required an effort he preferred to expand at the lab. He disliked excess in anything, voiced no cravings or needs apart from the frugal elements of his daily routine: cereal and tea in the mornings, a cup of tea after he got home, and two different vegetable dishes every night with dinner. He did not eat with the reckless appetite of Pranab Kaku. My father had a survivor's mentality" (Nossa tradução).
} 
mãe de volta ao mundo que havia deixado para casar-se com meu pai (LAHIRI, 2008, p. 65). ${ }^{9}$

Curiosamente, a proximidade entre os dois não causa ciúmes a Shyamal. Ao contrário, ele se sente grato pela companhia que Pranab proporciona a Aparna, o que, de certo modo, minimiza a sua culpa por tê-la afastado dos parentes. Mesmo sendo uma mulher tradicional, apegada às normas de conduta feminina típicas de seu povo, Aparna agarra-se aos momentos que compartilha com o rapaz, como um meio de suportar a existência em um país estrangeiro.

Em Reflexões sobre o exílio, Edward Said afirma que os imigrantes possuem uma percepção contrastiva, considerando que, para um exilado, hábitos, atividades ou mesmo o modo de expressar-se inevitavelmente reacendem a memória de outro meio ambiente (SAID, 2002, p. 186). No exílio, Aparna tenta recuperar algo do seu lugar antropológico ${ }^{10}$ por meio do seu relacionamento com Pranab.

Por outro lado, sob a pele da tradição, há uma mulher que inveja a possibilidade dos ocidentais casarem-se por amor. Embora não cogite abandonar a família por Pranab, a presença dele faz com que ela possa desfrutar indiretamente esse prazer. A chegada de Deborah desequilibra a sua visão do paraíso.

As demonstrações públicas de carinho entre Pranab e Deborah não afetam apenas os sentimentos de Aparna. Usha também experimenta certo desconforto em relação a isso:

Às vezes, eles acabavam dando comida um ao outro, deixando seus dedos
tocarem a boca um do outro, fazendo com que meus pais olhassem para seus
pratos e deixassem o momento passar. Em meio a um número maior de
pessoas, eles se beijavam e andavam de mãos dadas à frente de todos, e
quando estavam distantes o suficiente para não ouvirem, minha mãe
comentava com outras bengalesas. "Ele era tão diferente. Não compreendo
como uma pessoa pode mudar tão repentinamente. É tipo inferno-céu, a
diferença", ela dizia, sempre usando as palavras inglesas para a sua
autoforjada metáfora (LAHIRI, 2008, p. 69). Eu não vi nenhum sinal do fim de seu relacionamento. Sua afeição recíproca era tão franca, a felicidade que expressavam com facilidade, era uma coisa nova e romântica para mim (LAHIRI, 2008, p. 69). ${ }^{11}$

\footnotetext{
9 "Within a few weeks, Pranab Kaku had brought his reel-to-reel over to our apartment, and he had played for my mother medley after medley of songs from the Hindi films of their youth. They were cheerful songs of courtship, which transformed the quiet life in our apartment and transported my mother back to the world she'd left behind in order to marry my father" (Nossa tradução).

${ }^{10}$ De acordo com Marc Augé, o lugar antropológico é considerado relacional, histórico e identitário.

11 "Sometimes they ended up feeding each other, allowing their fingers to linger in each other's mouth, causing my parents to look down at their plates and wait the moment to pass. At larger gatherings, they kissed and held hands in front of everyone, and when they were out of earshot my mother would talk to the other Bengali women. "He used to be so different. I don't understand how a person can change so suddenly. It's just hell-
} 
Nem mãe nem filha estão acostumadas à revelação pública do afeto. Se para Aparna a mudança de comportamento de Pranab é como uma diferença entre "céu e inferno", metáfora que espelha, não as atitudes do rapaz, mas aquilo em que sua vida se transformara após o aparecimento de Deborah, para Usha aquela forma de amor, nunca antes sentida de modo tão próximo, é uma revelação.

A recusa dos pais de Pranab em aceitar o casamento resulta em uma chamada telefônica no meio da noite, permeada de acusações a Shyamal e Aparna, por terem apoiado um enlace que contrariava os planos da família: Pranab já tinha uma noiva prometida em Calcutá, com quem deveria casar-se. Ao fim da conversa, os pais do jovem ameaçam deserdá-lo; ameaça de que o jovem nunca toma conhecimento, graças à discrição do casal.

A intervenção da família de Pranab e sua expectativa quanto ao futuro do jovem demonstram uma conformidade com o modelo colonizador/colonizado que ainda perdura na Índia. Ele fora enviado à América para completar sua educação e retornar à terra natal, reproduzindo, assim, uma cultura colonial que deveria estar extinta, mas estende seus tentáculos ao mundo contemporâneo sob a forma de dependência cultural. Embora o colonialismo tenha findado, ao menos politicamente, em 1947, na Índia, a sua ideologia encontra-se entranhada na identidade cultural, tornando-se perceptível nas práticas sociais, econômicas e políticas.

A postura desafiadora de Pranab está em consonância com o comportamento e ambição de muitos imigrantes de primeira geração no mundo contemporâneo. Longe de indicar hesitação quanto a uma definição identitária, ela revela a emergência disruptiva de uma nova autorreferência: aquela que emana do "terceiro espaço" de Homi Bhabba. O casamento com Deborah, que terminaria vinte e três anos depois, reflete a dificuldade das relações interraciais, porém, em última instância, demonstra o livre arbítrio, o direito de escolha.

O cruzamento de fronteiras culturais, na maioria dos casos é traumático, mas na ficção de Jhumpa Lahiri ele é atenuado pelo suporte dos conterrâneos. Se para os imigrantes de primeira geração era essencial estabelecer essa rede, de modo a facilitar a integração dos imigrantes de uma mesma origem, para os das gerações seguintes ela assume um caráter

heaven, the difference", she would say, always using the English words for her self-concocted, backward metaphor" (Nossa tradução).

"I saw no sign of their relationship foundering. Their open affection for each other, their easily expressed happiness, was a new and romantic thing to me" (Nossa tradução). 
diferente. A rede já não tem mais o caráter primordial de manutenção da tradição, mas o traço distintivo de espaço transitório para o surgimento de identidades híbridas.

De certo modo, há afinidades entre as posturas de Pranab e Usha, pois ambos desejam livrar-se da obrigatoriedade de manutenção de crenças e tradições que não são suas, mas de seus ancestrais. Para Pranab, o caminho se abre através do casamento; para Usha na transformação de Deborah em um modelo a ser seguido: o de uma mulher norte-americana.

No dia do casamento de Pranab, pela primeira vez, Usha ousa demonstrar publicamente o seu desagrado por a mãe obrigá-la a manter um padrão de comportamento que destoa do das outras crianças de sua idade, em nome da tradição. Anos mais tarde, Amarna e Shyamal criticam o modo como Pranab e Deborah educam suas filhas: crianças que mal pareciam indianas, que só falavam inglês, que não eram obrigadas a ir a Calcutá todos os anos em visita às famílias de seus pais. Essas crianças eram objeto de inveja para Usha. Orgulhosa de suas tradições, Aparna vê Deborah como uma antítese de si mesma, o tipo de mulher que ela se recusa a ser. No entanto, seu desagrado não resulta da divergência de posturas sociais, nem deriva do fato de que ela pode vir a tornar-se uma má influência para Usha, que começa a lutar por sua independência. Na realidade, Deborah é a mulher que lhe roubou a porção “celestial" de sua existência, a parte prazerosa de sua vida: a convivência com Pranab.

À medida que cresce, Usha passa a perceber a limitações da mãe e as suas necessidades insatisfeitas e reage com a indiferença típica de uma primeira geração de americanos em uma família de imigrantes:

Eu aprendi a esconder coisas dela, com ajuda dos meus amigos. Eu lhe dizia que estava dormindo na casa de uma amiga, quando, na realidade, ia a festas, bebia cerveja e deixava que os rapazes me beijassem e tocassem meus seios, pressionando suas ereções contra o meu quadril quando estávamos nos apalpando em um sofá ou no banco de trás de um carro. Eu comecei a ter pena da minha mãe; à medida que crescia, eu percebia mais e mais a vida desolada que levava. Ela nunca trabalhara e passava o dia assistindo novela para matar o tempo. Sua única ocupação, todos os dias, era limpar e cozinhar para meu pai e eu (...) quando minha mãe reclamava com ele do quanto ela odiava a vida no subúrbio e como se sentia só, ele nada dizia para acalmá-la. "Se está tão infeliz, volte para Calcutá", dizia, deixando claro que a separação não o afetaria. Eu comecei a fazer o mesmo que ele ao lidar com ela, isolando-a duplamente (LAHIRI, 2008, p. 76). ${ }^{12}$

\footnotetext{
12 "I began keeping other secrets from her, evading her with the aid of my friends. I told her I was sleeping over at a friend's when really I went to parties, drinking beer and allowing boys to kiss me and fondle my breasts and press their erections against my hip as we lay groping on a sofa or the backseat of a car. I began to pity my mother; the older I got, the more I saw what a desolate life she led. She had never worked, and during the day she watched soap operas to pass the time. Her only job, every day, was to clean and cook for my father and me (...) when my mother complained to him about how much she hated life in the suburbs and how lonely she felt, he said nothing to placate her. "If you are so unhappy, go back to Calcutta", he would offer, making it clear that
} 
Muito embora Aparna tenha contato com outras mulheres indianas que compõem o seu restrito meio social, ela tem de enfrentar sozinha a solidão. Anos mais tarde, quando Deborah e Pranab se divorciam, ela é involuntariamente eleita a confidente de sua rival:

\begin{abstract}
Seus corações tinham sido partidos pelo mesmo homem, apenas o de minha mãe tinha sido remendado há um longo tempo atrás, e, de um modo estranho, quando meus pais envelheceram, começaram a gostar mais um do outro, quem sabe devido ao hábito. Acredito que a minha ausência, uma vez que estava na faculdade, tenha tido alguma importância nisso, pois, com o passar dos anos, quando eu os visitava, sentia um calor entre eles que nunca havia estado lá, uma implicância discreta, uma solidariedade, uma preocupação com o outro se um deles estivesse mal. Minha mãe eu também tínhamos entrado em acordo. Ela já aceitava o fato de que eu não era apenas sua filha, mas uma filha da América também (...) depois de anos sem fazer nada, ao chegar aos cinquenta, ela decidiu ingressar no curso de biblioteconomia de uma universidade próxima (LAHIRI, 2006, p. 81). ${ }^{13}$
\end{abstract}

O conto termina em um tom de intimidade entre mãe e filha, quando Aparna conta a Usha, cujo coração também fora partido por um homem com quem esperava casar-se, que ela mesma quase tinha cometido um erro terrível no passado, quando pensara em suicidar-se depois do casamento de Pranab. Ela havia espalhado solvente nas próprias roupas e estava para riscar um fósforo quando foi interrompida por uma vizinha. Ao chamá-la e comentar o quanto o pôr do sol estava lindo, a Sra. Holcomb havia mostrado a Aparna o absurdo do que pretendia fazer.

\title{
Últimas palavras sobre a história de um outsider...
}

Aparna constitui um exemplo da crise gerada pelo deslocamento. Ao acompanhar o marido em sua partida para a América, ela deixou para trás sua identidade, os laços que a atavam à terra natal e ao seu povo. A indiferença de Shyamal tornara tudo pior, ao ponto de anulá-la completamente. A intrusão de Pranab em sua vida tivera o efeito de um oásis em

their separation would not affect him one way or the other. I began to take my cues from my father in dealing with her, isolating her doubly" (Nossa tradução).

13 "Their hearts had been broken by the same man, only my mother's had long ago mended, and in an odd way, as my parents approached their old age, she and my father had grown fond of each other, out of habit if nothing else. I believe my absence from the house, once I left for college, had something to do with this, because over the years, when I visited, I noticed a warmth between my parents that had not been there before, a quiet teasing, a solidarity, a concern when one of them fell ill. My mother and I had also made peace; she had accepted the fact that I was not only her daughter but a child of America as well(...) after years of being idle, she decided, when she turned fifty, to get a degree in library science at a nearby university" (Nossa tradução) 
meio ao deserto. Embora certa de que jamais deixaria de lado as suas obrigações de esposa e mãe, ela não estava preparada para enfrentar o fato de que ele era um jovem, que cedo ou tarde apaixonar-se-ia por alguém. Sua forma destrutiva de ciúme era fruto de sua baixa autoestima e insegurança.

Por outro lado, Usha experimenta plenamente o processo de integração. Ela não aceita a superimposição das raízes indianas em sua vida. Ela se sente uma filha da América, o produto do intercâmbio de culturas. Embora não rejeite totalmente sua origem, ela não deseja ser aprisionada por elas.

$\mathrm{Na}$ realidade, Usha compartilha com a autora do romance um tipo de ambivalência identitária. Em uma de suas entrevistas, Jhumpa Lahiri (2006) afirmou que o que a levou à escrita foi o desejo de forçar os dois mundos a que pertence a unirem-se em uma única página, uma vez que ela não era corajosa ou madura o suficiente para fazê-lo em sua própria vida. Essa é, pois, a razão de estar sempre a escrever sobre imigrantes indianos na América, que tentam transitar entre os valores culturais de sua terra natal e aqueles da pátria de adoção, bem como sobre as divergências entre as diversas gerações de família imigrantes nos Estados Unidos, visto que as últimas, invariavelmente, se distanciam das restrições impostas pelos pais, ainda devotados ao senso de comunidade e de responsabilidade em relação aos conterrâneos:

\begin{abstract}
Neste livro, eu dispensei mais tempo aos personagens que não são imigrantes, mas seus descendentes. Eu acho isso interessante porque quando você é filho de um imigrante você está sempre - ou pelo menos eu estavamuito consciente do que significa ou pode significar ser desenraizado. Temse consciência disso, mesmo sem tê-lo feito. Eu sabia o que meus pais tinham passado por não se sentirem enraizados (CHOTINER, 2008). ${ }^{14}$
\end{abstract}

A resistência de Usha à tentativa materna de mantê-la em contato com a cultura e a tradição indianas deve-se à sua necessidade de construir a própria identidade, bem como de estabelecer um conjunto de valores pessoal. Entretanto, é fato que sucessivas gerações de imigrantes tornaram-se inevitavelmente assimiladas à cultura norte-americana, distanciandose cada vez mais dos valores culturais de seus ancestrais.

\footnotetext{
14 "In this book I spend more time with characters who are not immigrants themselves but rather the offspring of immigrants. I find that interesting because when you grow up the child of an immigrant you are always - or at least I was - very conscious of what it means or might mean to be uprooted or to uproot yourself. One is conscious of that without even having ever done it. I knew what my parents had gone through - not feeling rooted (Nossa tradução).
} 
Quanto a esse aspecto, é possível identificar abordagens diferentes do tema da imigração na obra de Lahiri. Seu primeiro livro foi quase que totalmente dedicado aos imigrantes de primeira geração e à sua luta para manter uma família em um país estranho. Unaccustomed earth, no entanto, parte desse ethos original mergulhando em um processo de aculturação já consumado.

O processo criativo de Lahiri deriva de uma memória étnica que é coletivamente construída, mas não efetivamente experimentada pelas gerações tardias de imigrantes, funcionando como uma memória de segunda mão. Ainda assim, os laços culturais persistem e não podem ser ignorados, apesar da integração ao país de adoção. O romance assume, assim, a feição de um ajuste de contas da autora com a sua identidade hifenada.

\section{Referências bibliográficas:}

AUGÉ, Marc. Non-places: introduction to an anthropology of supermodernity. London; New York: Verso, 1995.

BERRY, J. W. Conceptual approaches to acculturation. In: CHUN, K. M.; ORGANISTA, P. B.; MARÍN, G. (Eds.). Acculturation: advances in theory, measurement and applied research. Washington, D.C.: American Psychological Assoc., 2003, pp. 17-37.

CHOTINER, Isaac. Interviews: Jhumpa Lahiri. The Atlantic. Accessible on: http://www.theatlantic.com/magazine/archive/2008/03/jhumpa-lahiri/6725/. Retrieved on 2008-04-12.

HUGGAN, Graham. Exoticism and ethnicity in Michael Ondaatje's running in the family. Writing ethnicity. In: SIEMERLING, Winfried (Ed.). Cross-cultural consciousness in Canadian and Quebecois literature. Toronto: EWC Press, 1996.

LAHIRI, Jhumpa. Unaccustomed earth. New York: Vintage, 2008.

. The namesake. New York: Houghton Mifflin Harcourt, 2004.

Interpreter of maladies. New York: Houghton Mifflin, 1999.

My two lives. Newsweek. http://www.thedailybeast.com/newsweek/2006/03/05/my-

two-lives.html . Retrieved on 2011-12-03.

NAGPAL, Dominique. Between Heaven and Hell - perceptions of home and the homeland in Jhumpa Lahiri's work. Master thesis (2009). http://www.grin.com/en/ebook/140969/between-heaven-and-hell-perceptions-of-home-and-the-homeland-in-jhumpa\#tin side. Retrieved on 2011-12-15.

RUSHDIE, Salman. Imaginary homelands: essays and criticism, 1981-1991. London: Granta Books, 1991. 
SAID, Edward. Reflections on exile and other essays. Cambridge, MA: Harvard University Press, 2002.

WILTZ, Teresa. The writer who began with a hyphen. Jhumpa Lahiri, between two cultures. Washington Post. Acessible on http://www.washingtonpost.com/ac2/wp-dyn/A5925620030ct7?language=printer. Retrived on 2011-12-03.

The representation of the identity in "Hell-Heaven", by Jhumpa Lahiri

\begin{abstract}
This article aims at the analysis of the short-story "Hell-Heaven", by Jhumpa Lahiri, in order to demonstrate how the author deals with the issue of the immigrant's identity, as well as with the successive stages of the process of the immigrant's integration to the adopted country.
\end{abstract}

Key words: Identity. Immigration. Transculturation. 